\title{
La Junta de Patrimonio de Italia: un laboratorio político (I576-|596)
}

\author{
The Junta de Patrimonio of Italy: \\ A Political Laboratory (1576-1596)
}

\section{SYLVAIN ANDRE}

Sorbonne Université

Institut d'études ibériques et latino-américaines

CLEA (EA-4083)

31, rue Gay Lussac

75005 Paris (France)

sylvain2.andre@gmail.com

RECIBIDO: FEBRERO DE 202

ACEPTADO: MARZO DE 202

Resumen: El artículo analiza las particularidades de la Junta de Patrimonio de Italia, activa entre 1576 y 1596. A través de la presentación de sus miembros, los dos primeros apartados tratan de perfilar la lógica socio-gubernamental que subyace en su creación. Formada por miembros permanentes y provisionales, el cariz de este órgano presenta particularismos hasta la fecha ignorados por la historiografía. En la segunda parte nos detendremos en analizar dos casos que permiten medir la finalidad de la Junta y, sobre todo, su funcionalidad en la toma de decisión regia. Así, las consultas de la Junta en torno a la numeración del reino de Nápoles (1590) y al tema de las visitas de inspección (I576) permiten arrojar alguna luz sobre el dinamismo de los procedimientos de la concertación política y sobre la necesidad, a partir del último tercio del siglo XVI, de dinamizar las herramientas de la negociación entre la corona y los reinos.

Palabras clave: Junta de Patrimonio. Gobierno. Italia. Numeración. Visitas de inspección

Abstract: The article analyses the particularities of the Junta de Patrimonio of Italy, active between 1576 and 1596. Through the presentation of its members, the first two sections attempt to outline the socio-governmental logic behind its creation. Made up of permanent and provisional members, the nature of this body has particular features that have been ignored by historiography to date. In the second part, we will analyze two cases that allow us to measure the purpose of the Junta and, above all, its functionality in royal decision making. Thus, the Junta's consultations on the numbering of the Kingdom of Naples (1590) and on the subject of inspection visits (1576) shed light on the dynamism of the political consultation procedures and on the need, from the last third of the 16th century, to revitalize the tools of negotiation between the crown and the kingdoms.

Keywords: Junta de Patrimonio. Government. Italy. Numbering. Inspection visits 
El recurso cada vez más frecuente a Juntas especializadas a partir de los años 1570 se manifestó, si bien progresivamente, en la casi totalidad de las áreas del gobierno'. No cabe duda de que la influencia de los hombres del cardenal Espinosa, entre los cuales destaca la figura de Juan de Ovando, fue determinante: desde la Junta Magna (I568) hasta la Junta de Presidentes (I574), pasando por la Junta de Indias (I57I) o también la Junta de Reformación (1574), una modalidad nueva de gestión de la información en la corte estaba en gestación, una modalidad más flexible y por tanto adaptable a las más diversas coyunturas ${ }^{2}$. Las páginas que siguen se centran en el estudio de una de las primeras Juntas dedicadas a los asuntos italianos: la Junta de Patrimonio de Italia, creada en I576.

A juicio de Manuel Rivero,

este organismo se dedicó tanto a concebir remedios para sanear las arcas reales, buscando la disminución de los gastos ordinarios y el aumento de los ingresos, como también a la gestión de estos asuntos hasta el año $1579^{3}$, cuando se reformó de nuevo el gobierno y la administración de Italia ${ }^{4}$.

En esta presentación general de la Junta, Rivero basa su interpretación en la coyuntura particular - que el historiador califica de reformista- de I579, año en el que el cardenal Granvela fue nombrado presidente del Consejo de Italia y en el que se redactaron tres instrucciones: una para modificar los atributos y prerrogativas del Consejo de Italia ${ }^{5}$; otra que redefinía las tareas del secretario de dicho Consejo ${ }^{6} ; y$, por último, otra más que instituía un nuevo oficio, el Conservador del Patrimonio de Italia, que recayó en Juan Antonio Dancora, miembro a la sazón de la Junta de Patrimonio?.

\footnotetext{
I André, 2018a.

${ }^{2}$ André, 2019.

${ }^{3}$ Como ocurre a menudo con esos órganos informales del poder, resulta difícil fijar con certeza los límites cronológicos de la existencia de esta Junta. Si el año 1576 aparece a todas luces como la fecha de su creación, el momento de su desaparición sigue siendo dudoso. En este trabajo, tomaremos 1596 como punto de cierre, pues es en aquella fecha cuando desaparecen las huellas de sus consultas y deliberaciones.

${ }^{4}$ Rivero Rodríguez, 1998b, p. 133.

${ }^{5}$ «Papeles históricos referentes al reino de Nápoles», Biblioteca Nacional de España [BNE], Mss. 988.

6 «Instrucciones al secretario Zayas» (20 de octubre de 1579), BNE, Mss. II67.

7 «Título de conservador del Patrimonio y hacienda de Italia en Juan Antonio Dancora y la instrucción que ha de guardar» (20 de octubre de 1579), Archivo General de Simancas [AGS], Secretarías Provinciales [SSP], Nápoles, lib. 63. Sobre la simultánea redacción de estos tres documentos, ver «Billete de Granvela a Mateo Vázquez» (2I de octubre de I579), Instituto Valencia de Don Juan [IVDJ], E. 47, C. 6I, doc. I37: «A las diez de la mañana y no antes me dieron hoy el pliego de v. m. y por esto no he ido al Consejo porque fue tarde para llamar los regentes. $Y$ con su billete he recebido la instrucción para el consejo y para el secretario y el título de conservador para Juan Antonio de Ancora. Hacerse ha todo lo que conviene. A Francisco de Idiáquez se le da aviso de lo que le toca para que quede con la quietud que es razón. Y mañana hará el juramento en el Consejo Real que hoy no se ha podido hacer, habiéndole ya hecho dende antayer don Juan de Idiáquez. Vista la instrucción de secretario de Italia tengo por cierto que quedará contento el secretario Zayas y si no,
} 


\section{LA JUNTA DE PATRIMONIO DE ITALIA}

Siguiendo la lectura de Rivero, los ejes de esta gran fase reformista del gobierno italiano eran los siguientes:

I. Distanciamiento entre los miembros de los Consejos y los territorios administrados en nombre de una mejor eficacia. Se trataba concretamente de evitar colusiones entre intereses personales y acción de gobierno.

2. Clarificación de la relación entre el Consejo de Italia y los virreyes y gobernadores, con una voluntad de subordinar la acción del segundo a las deliberaciones y decisiones del primero ${ }^{8}$.

3. Homogeneización del gobierno del conjunto de territorios italianos que se conciben según una perspectiva global y ya no particularista. Esta evolución, obviamente, había corrido paralela con el distanciamiento entre asuntos aragoneses e italianos, inducido por la creación del Consejo de Italia en I556. De aquí en adelante, los regentes del Consejo habrían de tratar de forma colegiada los asuntos italianos poniendo fin a un tratamiento diferenciado de cada territorio.

4. Consolidación de la jerarquía interna del Consejo de Italia, con un aumento significativo del poder del presidente.

La interpretación general de Rivero se fundaba en la idea de que esta gran fase de reformación tenía como finalidad la centralización del gobierno y traducía la voluntad de dominar las posesiones italianas de la monarquía a través de la racionalización de las herramientas de gobierno y el control de los oficiales y las instituciones de gobierno tanto en Madrid como en Italia. En última instancia, esta centralización había de conferir eficacia a la gestión del servicio al rey.

Contemporánea de los trabajos de Rivero, fue desarrollándose en Italia una historiografía deseosa de redefinir el lugar que ocupaban unos territorios concebidos como una totalidad, o como una unidad, gobernados de una manera más o menos lógica o coherente, y en todo caso global. Esta fue la línea defendida por Giuseppe Galasso y Giovanni Muto?. Este fue también, aunque de forma un poco diferente, el enfoque de Aurelio Musi en su artículo titulado: «El reino de Nápoles y el sistema imperial español», publicado en 1998, en una de las múltiples publicaciones de la Universidad Autónoma de Madrid con ocasión del cuarto centenario de la muerte de Felipe ${ }^{110}$.

No se trata aquí de proponer una revisión historiográfica de estas interpretaciones sino de completarlas y acaso, en algunos aspectos, matizarlas. Quisiera mostrar que el movimiento global del periodo estudiado - desde mediados de los 70 hasta mediados de los 90 del siglo XVI- no tendió solamente hacia una

entenderemos lo que dirá. Guarde Nuestro Señor...»

${ }^{8}$ Para el caso milanés del gobernador, Álvarez-Ossorio, 2001.

9 Muto, 2012.

10 Musi, 1998. 
«domesticación» de los consejeros y los ministros en Madrid, ni hacia una anulación pura y simple de la acción individual de estos personajes en beneficio de una acción colegiada centralizada, ni de forma exclusiva hacia la subordinación de las instituciones de los reinos italianos comprendidos como un conjunto territorial más o menos homogéneo o coherente; quisiera mostrar que el periodo también se orientó hacia una diversificación de los instrumentos de gobierno, hacia la potenciación de amplias redes informativas y hacia la multiplicación de los espacios de negociación con los territorios italianos.

Las dos primeras partes de este artículo van dedicadas al estudio de los actores que formaron parte de la Junta. Más allá de sus competencias individuales y de su calidad de letrados o no, nos interesaremos por la lógica que explicaba su reunión en un colegio específico. Asimismo, trataremos de perfilar a uno de estos personajes, aquel que, habiendo empezado a trabajar en la Junta, fue nombrado en 1579 Conservador del patrimonio de Italia.

La tercera parte analiza dos casos, dos procesos consultivos en los que participó la Junta, y persigue el objetivo de comprender cuál fue, para Felipe II y sus más próximos consejeros, el valor añadido de recurrir a una Junta especializada y a qué resultados dio lugar en términos de decisión política.

\section{UNA PLANTILLA NOVEDOSA. CONSEJEROS, «FUNCIONARIOS AMBULANTES» Y EXPERTOS PROVISIONALES}

Antes de proceder al análisis de las deliberaciones de la Junta, cabe resaltar las dos categorías de actores, claramente identificables, que componían su plantilla". En efecto, la tipología misma de los personajes que fueron llamados a participar a la Junta en los inicios de su creación configuró de una manera muy específica la funcionalidad del nuevo colegio.

El primer grupo lo componían los secretarios y consejeros que oficiaban en el entorno real, y que intervenían en Consejos y Juntas. La lista, aunque amplia para una Junta, no es tan larga, y los nombres son todos muy conocidos por la historiografía: Diego de Cabrera y Bobadilla, tercer conde de Chinchón, que acababa de heredar de su padre, aquel mismo año de 1576, el oficio de Tesorero General de la Corona de Aragón ${ }^{12}$; Mateo Vázquez, convertido desde la muerte del cardenal Espinosa en 1572 en el secretario personal del rey ${ }^{13}$; Francisco de

\footnotetext{
II Billete de Felipe II, IVDJ, E. 45, C. 59, doc. 402.

12 Fernández Conti, 1994.

${ }^{13}$ Escudero, 2002.
} 


\section{LA JUNTA DE PATRIMONIO DE ITALIA}

Liévana ${ }^{14}$ y Francisco de Ávalos, ambos íntimos colaboradores del famoso presidente de Indias y de Hacienda Juan de Ovando, fallecido el año anterior; el contador Garnica ${ }^{15}$ y, por fin, Antonio Pérez, cuya carrera no tardaría en verse truncada en el transcurso de un famosísimo capítulo de la historia del reinado de Felipe II. Además de ser todos hombres influyentes en la corte, cercanos al rey, miembros en su mayoría de la red de poder de Mateo Vázquez, es de subrayar que eran casi todos letrados ${ }^{16}$. Asimismo, no es de sorprender, tratándose de una Junta de Patrimonio, que salvo contadas excepciones fueran también especialistas financieros. Finalmente, los únicos expertos en asuntos italianos eran Antonio Pérez, secretario del Consejo de Italia, y Leonardo de Herrera, regente castellano de Milán en dicho Consejo ${ }^{17}$.

La segunda categoría en la Junta estaba formada por regentes y oficiales «italianos» ${ }^{18}$ : Hernando de Montenegro, antiguo miembro del Consejo Colateral de Nápoles, Baltasar de Molina, Conservador del Patrimonio de Milán, el regente Cutinario, Conservador del Patrimonio de Sicilia y Juan Antonio Dancora que, como lo hemos mencionado anteriormente, habría de convertirse en 1579 en el primer Conservador del Patrimonio de Italia. Hasta ese momento, la carrera de esos hombres se había desarrollado exclusivamente en los territorios italianos, y en alguna ocasión en varios de ellos. Gracias a ellos, la Junta contaba con expertos en contabilidad (dos Conservadores), antiguos consejeros de las instituciones locales dedicadas al gobierno (Consejo Colateral) y un especialista fiscalista de la corona de Aragón (Dancora).

Al sumar diez miembros, la plantilla de la Junta de Patrimonio de Italia era relativamente amplia en comparación con otras de la misma época. Al respecto, resulta significativo que a los pocos días Felipe II escribiera: «las personas son muchas pero no creo que se ha podido excusar ninguna» ${ }^{19}$. Ahora bien, si nos centramos en el conjunto de los perfiles de los miembros de la Junta, nos damos cuenta de que, entre todos, eran hombres que conocían los mecanismos de la consulta y las deliberaciones en la corte, con especial dominio en temas hacendísticos; que, asimismo, eran hombres que dominaban el funcionamiento de las instituciones locales de gobierno de las finanzas reales - derecho, estructura de gobierno, etc. - ; en fin, eran hombres al tanto de las realidades locales, los usos,

\footnotetext{
${ }^{14}$ Rivero Rodríguez, 2014.

15 Martínez Millán y de Carlos Morales, 1998.

${ }^{16}$ Las dos excepciones eran precisamente los dos hombres fuertes de esta red de poder: el conde de Chinchón y Mateo Vázquez.

17 Álvarez Ossorio, 200I, p. 34.

18 IVDJ, E. 45, C. 59, doc. 402.

${ }^{19}$ Billete de Felipe II a Mateo Vázquez (4 de noviembre de 1576 ), IVDJ, E. 53, C. 69, doc. 426.
} 
las costumbres y las prácticas sociales del poder. En esta amplia gama de pericias se encuentra, en nuestra opinión, una de las razones de la creación de la Junta de Patrimonio de Italia. En efecto, todo parece indicar que para Felipe II, lo importante -aquello que le había impedido "excusar ninguna» persona- se situaba en el equilibrio entre diferentes saberes y experiencias, en la complementariedad de los conocimientos y en la diversidad de opiniones.

Sin embargo, la composición de la Junta no era a priori tan diferente de la del Consejo de Italia. Al reunir dos regentes por cada territorio - dos para Nápoles, dos para Milán y dos para Sicilia-, siendo uno de cada pareja un oficial «italiano» y el otro «castellano» ${ }^{20}$, el Consejo de Italia también reunía hombres que permitían la confrontación entre, digamos, visiones localistas y visiones de la corte. Pero el Consejo, desde su instauración a principios del reinado, venía limitado por este marco jurisdiccional que le obligaba a mantener un equilibrio entre los territorios italianos y entre consejeros de la corte y consejeros cuya carrera se había iniciado en Italia. La Junta, en cierto modo, había de permitir superar los estrictos límites impuestos por el marco territorial y jurisdiccional del Consejo. Además, la participación en ella de tan gran número de especialistas, muchos de los cuales no procedían del área política italiana, había de favorecer la inserción de los asuntos italianos dentro de una lectura más global del gobierno de la monarquía. Esta manera de rebasar no solamente el marco legal que regía los Consejos sino también las divisiones jurisdiccionales que estructuraban el conjunto del régimen polisinodial, fue una tendencia general del periodo que culminó con la creación de la Junta personal de Felipe II, aquella conocida como Junta de Noche, a finales de los años $1580^{21}$. Sea lo que fuere, de esta configuración inicial de su plantilla resultó la funcionalidad tan peculiar de la Junta de $\mathrm{Pa}$ trimonio y el impacto que tuvo en las modalidades de acción del gobierno; unas modalidades, como veremos, bastante alejadas del autoritarismo regio defendido por buena parte de los consejeros en la corte.

No obstante, la mayor particularidad de esta Junta, respecto de otras de la misma época, estribaba en el hecho de componerse de una plantilla repartida entre miembros fijos - los secretarios y consejeros - y miembros provisionalmente llamados a la corte a participar en ella - los regentes y oficiales de los reinos italianos-. En efecto, mientras los hombres del rey hacían de coordinadores de los trabajos de la Junta, algunos incluso, como Mateo Vázquez o el conde de Chinchón, articulaban su actividad con los demás órganos de poder

\footnotetext{
${ }^{20}$ Rivero Rodríguez, 1998b.

21 André, 2020.
} 


\section{LA JUNTA DE PATRIMONIO DE ITALIA}

- Consejo de Italia, Contadurías y Tesorerías, Consejo de Hacienda-, los regentes aparecen como agentes móviles, oficiales itinerantes, encargados de acudir a Madrid para dar relación de unos acontecimientos, para compartir su experiencia y su conocimiento en determinadas materias, y luego mandados de nuevo a los distintos territorios con el fin de recaudar o trasmitir informaciones, llevar a cabo comisiones específicas o simplemente ocupar oficios en las instituciones locales ${ }^{22}$.

Gracias a este sistema de circulaciones entre ambas penínsulas, la Junta de Patrimonio de Italia pudo actuar como una plataforma dinámica de la información política relativa a Nápoles, Milán y Sicilia, y como un espacio privilegiado de negociación con los poderes locales y los múltiples actores de la hacienda regia en dichos territorios. De hecho, la presencia en la corte de aquellos oficiales italianos constituía una oportunidad para los madrileños de hacerse con amplias redes de informadores que asimismo efectuaban idas y vueltas:

También se le advierta a Filiodon de los feudos y cosas que se ha escrito y ordenado se vendan, $y$ de lo que más hubiere de vender que convenga venderse; $y$ que el dinero que se sacare desto sirva para las fortificaciones que se mandan hacer en aquel Estado por la necesidad que hay dellas, y no para otra cosa; y que también lleve orden de procurar con los pueblos que ayuden para las fortificaciones, como ya he dicho, pues han de ser para su beneficio y defensa. Todo esto se podrá tratar y platicar en su presencia, para que lo lleve mejor entendido, llamando a Garnica para ello y, no estando presente Filiodon, tratar de lo que será bien y justo hacer con él y de quién sería bien que viniese en su lugar ${ }^{23}$.

Este mecanismo configuró de una manera bastante nueva el desarrollo de la carrera de aquellos oficiales locales que fueron llamados a participar en las reuniones de la Junta. Recordemos, sobre esta cuestión, los tres modelos de carrera propuestos por Musi: «el modelo del camino vertical periferia-centro (Nápoles-Madrid); el modelo horizontal del curso interno a las Magistraturas de la Capital (Nápoles); y el modelo provincial» ${ }^{24}$. Dentro de esta tipología, la Junta de Patrimonio de Italia parece ofrecer otra vía más, una vía más circulatoria,

\footnotetext{
22 Aunque es difícil seguir en el tiempo las evoluciones de la plantilla de la Junta, las fuentes parecen indicar que se mantuvo este equilibrio entre miembros fijos y miembros provisionales. De la segunda categoría se pueden mencionar los casos del procurador Ferrante Fornaro: abogado fiscal en Nápoles en 1590, miembro de la Junta a partir de 1592 y de nuevo lugarteniente de la Sumaria en 1593; el de Mateo Ferro, lugarteniente de Juan Antonio Dancora, que entró en la Junta cuando fue nombrado a su vez Conservador, a la muerte de su predecesor; y el de Luis de Barahona, antiguo gran canciller de Nápoles, Teniente del Tesorero General de la Corona de Aragón (el conde de Chinchón) y miembro de la Junta de Patrimonio.

23 Billete de Felipe II a Mateo Vázquez (12 de abril de 1579), Riba García, 1959.

24 Musi, 1998, p. 564.
} 
multidireccional, en la que el acceso a la Junta, en la corte, deja de aparecer como un objetivo último en el juego ascensional de los actores.

De forma general, las Juntas no estaban sometidas a las mismas condiciones jurisdiccionales que los Consejos, sino que con ellas el rey barajaba y volvía a barajar constantemente a aquellos hombres que habían de ser capaces de ofrecerle las soluciones más aplicables, las decisiones menos susceptibles de levantar resistencias $y$, además, de hacerlo por vía de deliberaciones lo más contrastadas posibles. Esta observación se hace todavía más patente en el caso de la Junta de Patrimonio, cuya plantilla era evolutiva. Puede ser - ciertos documentos lo sugieren- que esta lógica circulatoria fuera en detrimento de las expectativas de ascenso de los actores. Pero se observa en otros tantos casos que el acceso a las altas esferas del poder en Madrid, e incluso a veces el acceso directo al rey, aunque ocasional, compensaba con creces las decepciones que la vida cortesana podía reservar a los «extranjeros» ${ }^{25}$. En última instancia, cabe subrayar también la ventaja que podían sacar los actores políticos italianos de la presencia de sus miembros en la corte, algunos de ellos escogidos por el rey entre los más destacados. Gracias a esos hombres, los intereses locales gozaban de una representación mayor y más eficaz.

Volviendo una vez más a las muy sugerentes propuestas de Musi, creo oportuno retomar aquí el concepto de «funcionario ambulante» que forjara el historiador hace veinte años, pero con dos matices. El primero, que no conviene encerrar en exceso a estos funcionarios en itinerarios predeterminados: a pesar de las tendencias que se dibujan, cabe tener en cuenta el grado de autonomía que siempre conservaron los actores en el Antiguo Régimen, así como el dinamismo que la corona imponía a estas circulaciones. La segunda prevención es que este concepto no ha de suponer en ningún caso que existiera una forma única u homogénea de actuar como «funcionario» en Nápoles, Palermo o Milán.

Finalmente, el concepto de «funcionario ambulante», en el caso de la Junta de Patrimonio, podría verse completado por otro: el de «experto provisional» promovido por el propio rey. De funcionarios que iban y venían de una península a otra, los oficiales italianos se convertían, en la corte, en peritos ocasionales que habían de dirimir puntos a veces muy específicos, con ocasión de estancias de duración variable. Puede que esta noción de «experto provisional» no sea del todo inútil en un intento de renovar los paradigmas explicativos del recurso a Juntas en el Antiguo Régimen.

\footnotetext{
25 Peytavin, 1998.
} 


\section{LA JUNTA DE PATRIMONIO DE ITALIA}

Antes de pasar a examinar algunos resultados de las deliberaciones de la Junta de Patrimonio de Italia, quisiera esbozar un poco más este perfil de funcionario y experto a través de un ejemplo concreto, el de Juan Antonio Dancora, miembro de la Junta y, a partir de 1579, Conservador del Patrimonio de Italia.

\section{JUAN ANTONIO DANCORA, PRIMER CONSERVADOR DEL PATRIMONIO DE ITALIA}

La carrera de Juan Antonio Dancora anterior a su nombramiento al oficio de Conservador del Patrimonio de Italia nos es casi por completo desconocida. Amplias pesquisas en los depósitos del Archivo de la Corona de Aragón y de Simancas permitirían quizá descubrir más. Para lo que nos interesa aquí me limitaré a mencionar que antes de entrar en la Junta de Patrimonio, Dancora había tenido una larga carrera itinerante. Sirvió, en fechas difíciles de determinar, en Nápoles, Valencia y Mallorca ${ }^{26}$, y fue revisor de cuentas durante la visita de Milán de la primera mitad de los años 1560, donde coincidió con Baltasar Molina, antiguo Gran Canciller y revisor, como él, de las cuentas milanesas, y también con Leonardo Herrera y otros muchos:

Jerónimo Mamarela que fue llamado en el principio del año 1560 por don Andrés de la Cueva, Pedro Verdugo y Juan Antonio de Ancora, revisores de cuentas del Estado de Milán que serviese en la dicha revisión en lo que le fuese mandado por ser persona hábil y inteligente para semejantes cosas, el cual servió hasta que se fueron los dichos revisores por orden de V. M. Después fue por V. M. nombrado el gran canciller Barahona y por causa de su fallecimiento fueron el regente $\mathrm{He}-$ rrera y senador Palatio, para que en lugar de los sobredichos perseverasen y acabasen la dicha revisión y, de contino, el dicho Mamarela ha perseverado a riquesta dellos ${ }^{27}$.

Si bien es incompleta, la documentación tiende a presentar a Dancora como uno de los mejores especialistas en fiscalidad de la corona de Aragón, territorios italianos incluidos. En la corte, donde reside a partir de los años 70, se nos aparece como un hombre cercano al conde de Chinchón. Cuando empezó a pensar en aquellos hombres que habrían de formar la plantilla de la Junta de Patrimonio de 1576, Felipe II, dirigiéndose a sus principales coordinadores, escribió:

\footnotetext{
${ }^{26}$ IVDJ, E. 8, T. I, doc. 85.
}

27 IVDJ, E. 3I, C. 44, M, 7I. 
[...] y platíquese mañana si será bien que Juan Antonio Dancora y el Conservador de Sicilia entendiesen también en algo destas relaciones y apuntamientos que creo que tienen noticia de aquellas cosas y podrían ayudar a ellas ${ }^{28}$.

El rey se refería aquí a apuntes redactados por los regentes del Consejo de Italia, y que la Junta de Patrimonio habría de examinar. Dancora y Cutinario, el mencionado Conservador de Sicilia, habrían de servir de primeros examinadores de las propuestas del Consejo. Su conocimiento y su experiencia en Italia conferían a estos personajes un perfil de expertos capaces de evaluar la oportunidad de tal o cual propuesta de los regentes del Consejo de Italia. Desgraciadamente, hasta ahora, no hemos encontrado ningún memorial anotado por Dancora $^{29}$. Pero su labor como consejero en la corte debió de ser satisfactoria, pues en 1579 el rey decidió nombrarle primer Conservador del Patrimonio de Italia:

Habiendo sido informado lo mucho que importa a mi servicio que haya persona propia que particularmente tome y tenga a su cargo el mirar por nuestra hacienda y patrimonio de los reinos de Nápoles, y Sicilia y Estado de Milán, y considerando lo mucho y bien que vos, Juan Antonio Dancora, nos habéis servido en estas materias, así en Nápoles y Milán como en Valencia y otras partes de la corona de Aragón y confiando que de aquí adelante continuaréis esto mismo con la fidelidad y cuidado que hasta aquí, nos ha parecido nombraros, como por la presente os nombramos, por conservador general de todo nuestro patrimonio de los dichos tres estados de Italia durante nuestra mera y libre voluntad ${ }^{30}$.

Si bien el área de actuación del nuevo oficio instituido se limitaba a los «tres Estados de Italia», no en balde recalcaba Felipe II que la experiencia de Juan Antonio Dancora también se había ido forjando en los territorios ibéricos de la corona de Aragón. Además, el salario de 1200 ducados que había de cobrar anualmente el Conservador debía proceder de dos fuentes ${ }^{31}$ : mientras una mitad iba repartida a partes iguales entre Nápoles, Sicilia y Milán, la otra mitad se la pagaría el Tesorero general de la Corona de Aragón a cambio de «asistir en las cosas y negocios tocantes a aquella corona cuando se ordenare y mandare ${ }^{32}$.

Lo antes posible, tras recibir la cédula de su nombramiento ${ }^{33}$, Juan Antonio Dancora había de elaborar tres libros: «uno donde particular y distintamente se

28 IVDJ, E. 45, C. 59, doc. 402.

${ }^{29}$ Sobre las evaluaciones previas de memoriales, antes de su remisión a las Juntas o consejos competentes, André, 2019.

30 «Título de Conservador del Patrimonio y hacienda de Italia en Juan Antonio Dancora y la instrucción que ha de guardar, El Pardo, a 20 de octubre de I579», AGS, SSP, Nápoles, lib. 634.

${ }^{31}$ Archivo de la Corona de Aragón [ACA], Cancillería, Registros, núm. 4308, fol. 40.

32 AGS, SSP, Nápoles, lib. 634.

${ }^{33}$ Se la remitió el propio cardenal Granvela, nombrado presidente del Consejo de Italia ese mismo año, en la 


\section{LA JUNTA DE PATRIMONIO DE ITALIA}

tome la razón de todo el patrimonio y hacienda que tenemos en los dichos estados de Italia, dividiendo lo de cada uno del otro y poniéndolo año por año» ${ }^{34}$. Para simplificar, se trataba de conocer todos los ingresos de la monarquía procedentes de la otra península, lo cual suponía establecer la lista completa de las tierras y jurisdicciones de cada reino pertenecientes al rey, el valor de cada una, las formas y frecuencia de las recaudaciones, etc. Dicho de otro modo, Dancora había de elaborar una relación lo más pormenorizada posible del mosaico jurisdiccional de los tres reinos, así como una aproximación a su respectivo estado demográfico-fiscal.

El segundo libro estaba dedicado a los gastos relativos a la gracia real: mercedes, pensiones, ayudas de costa, pagas de oficiales, etc. Y el último libro debía reflejar todas las salidas de dinero hacia Italia, así pagos ordinarios como asientos firmados con mercaderes locales, etc. Esto significaba también, y así lo mandaba el rey, que de aquí en adelante Dancora se quedara con copia de todas y cada una de las libranzas y órdenes de pago firmados por el Consejo de Hacienda con destino a Nápoles, Milán y Sicilia.

En sus líneas principales, las instrucciones que recibió Dancora en 1579 eran muy parecidas a las que recibían secretarios, contadores, tenientes de tesoreros y otros hombres de pluma dedicados a asuntos hacendísticos. De hecho, las instrucciones, además de supeditar la acción de Dancora a las órdenes de Chinchón, también lo vinculaban directamente con el Consejo de Italia, en el que había de entrar «todas la veces que se tratare de cualquier negocio tocante o concerniente al dicho oficio» ${ }^{35}$, esto es: en cuestiones financieras y no de justicia. En resumidas cuentas, y retomando las palabras de Rivero, el Conservador era «un oficial que disponía de cierto rango de consejero, ya que, como asesor técnico para materias económicas, asistía a las sesiones en que estas se trataban, con voz pero sin votos ${ }^{36}$.

Se podría pensar que a partir de ese momento Dancora se convirtió en un mero oficial de pluma, igual a otros tantos que residían en la corte, entintando montañas de papeles con el fin de poner orden al imperio documental del Rey Católico ${ }^{37}$. Y la verdad es que, a pesar de la parquedad de las fuentes, no hallamos motivos para dudar de la descripción que de su oficio nos da Rivero:

[...] Su función principal era asistir al Tesorero en el control de los ingresos y gastos de hacienda y patrimonio real en Italia, supervisando la actividad de las

noche del 20 de noviembre de 1579 (IVDJ, E. 5, T. III, doc. 2I0).

34 «Título de Conservador del Patrimonio...», AGS, SSP, Nápoles, lib. 634.

35 «Título de Conservador del Patrimonio...», AGS, SSP, Nápoles, lib. 634.

${ }^{36}$ Rivero Rodríguez, 1998b, p. 160.

37 Gaudin, 2012. 
tesorerías y contadurías reales de aquellos territorios. Debía llevar la orden de las cuentas y aconsejar al Tesorero solo cuando se lo demandase, incluso en materias concernientes a la Corona de Aragón ${ }^{38}$.

Pero esto era solo parte de la realidad, pues el papel de Dancora a partir de 1579 no vino a reducirse a ser supervisor de las Contadurías y consejero personal del Tesorero. Además de estas tareas de despacho, Dancora siguió siendo un hombre dedicado a cumplir misiones puntuales en Italia y también en los territorios de la Corona de Aragón. En I58I, a los dos años de su nombramiento, está en Cataluña, llevando a cabo un proceso de capbrevación ${ }^{39}$, y lo mismo hizo, acompañado por un tal Menegat, en Aragón, posiblemente entre los años I584- I58640. En I59I está en Madrid y es invitado a participar en los trabajos de la Junta de Tanteo, ordenada por la Junta Grande ${ }^{41}$. En efecto, el arbitrista Gaspar de Pons, coordinador de la Junta de Tanteos había elegido a Juan Antonio Dancora, Pedro Luis de Torregrossa y Antonio de Guevara para, entre los cuatro, realizar un tanteo general por todos los territorios italianos ${ }^{42}$. Una amplia encuesta estuvo entonces a punto de realizarse en los territorios de la península itálica que habría de empezar en Mesina, que fue finalmente abandonada sin que, más allá de la muerte de Guevara, sepamos exactamente por qué razón.

Después de I59I no hemos encontrado más pruebas de que Dancora volviese a abandonar Madrid. De hecho, aquel mismo año nombró a un teniente para que le ayudara con sus tareas burocráticas ${ }^{43}$. Mateo Ferro, su teniente a partir de esta fecha, fue nombrado Conservador del Patrimonio de Italia a la muerte de Dancora en I594 o 1595.

Este perfil, modélico o no, es revelador de la originalidad de la Junta de Patrimonio. Cierto es que no todos los oficiales italianos de la plantilla de la Junta fueron tan móviles como pudo serlo Dancora. Tampoco se puede descartar la posibilidad de que algunos de ellos se quedaran en Madrid después de nombrados. Pero, de todos modos, este mecanismo imprimió a la Junta un dinamismo que no tenía el Consejo de Italia, por mucho que este incluyera a partes iguales agentes locales y consejeros castellanos. El ejemplo de Juan Antonio Dancora revela, a mi modo de ver, el papel que las Juntas, o al menos algunas de ellas, pudieron desempeñar en las evoluciones de la figura del consejero en la segunda

\footnotetext{
${ }^{38}$ Rivero Rodríguez, 1998b, p. 160.

39 IVDJ, E. I3, C. 24, doc. 178. Capbrevar o cabrevar: apear en los terrenos realengos las fincas que pagaban los derechos del patrimonio real.

40 IVDJ, E. I3, C. 25, doc. 300.

${ }^{41}$ Sobre esta Junta, André, 2018b.

42 IVDJ, E. 3I, C. 44, T. 10.

43 IVDJ, E. 45 , C. 58 , doc. 176
} 


\section{LA JUNTA DE PATRIMONIO DE ITALIA}

mitad del siglo XVI y, por tanto, en la redefinición del llamado «deber de consejo», entendido aquí no como concepción jurídico-política sino como praxis de gobierno ${ }^{4}$.

\section{MINIMIZAR LOS CONFLICTOS, DESARMAR LAS RESISTENCIAS}

Las instrucciones que recibió la Junta de Patrimonio de Italia, las encontramos en el billete mediante el cual el rey instauró la Junta:

Yo ha días que he querido mandar juntar algunas personas para tratar de lo que toca a la hacienda de Nápoles, Sicilia y Milán, así para que se mire en lo que podría y debría ver acrecentada, como en que se dé orden en la buena administración della y se excusen los gastos y cosas que creo que debe haber superfluos y impertinentes, de manera que haya con que suplir a las necesidades y gastos que allí se ofrecen y se pueden ofrecer, porque es menester que haya hacienda y se conserve y aumente o sea desempeñando lo que lo está, questo sería lo mejor, o cresciendo la renta en cosas justas de manera que no se pase la necesidad y trabajo que hasta aquí $^{45}$.

Desempeño, reducción de gastos y, eventualmente, aumento de las rentas constituían los ejes, ciertamente complementarios, del programa de trabajo de la Junta. Pero hay más: vemos en estas líneas, confirmadas en otros lugares, que de lo que se trataba era hacer que los territorios italianos se fueran autofinanciando ${ }^{46}$. La presencia en la Junta de dos de los tres Conservadores del Patrimonio - el de Milán y el de Sicilia- se hacía necesaria por ello: porque lo primero que se les acometió a los hombres de la Junta fue un balance del introito y gastos de cada una de las posesiones italianas de la monarquía. La finalidad era fomentar mecanismos de financiación internos en la otra península para evitar que Madrid tuviera que recurrir al patrimonio real. Si, como ocurrió en varias ocasiones, las cuentas de Nápoles eran deficitarias, el equilibrio había de buscarse en Milán donde la balanza financiera era excedentaria ${ }^{47}$. La mención tan frecuente en la documentación del "gobierno de Italia» o de la «hacienda de Italia» no remite sino a esta autonomía financiera. Por lo demás, los miembros de la Junta tendieron siempre a examinar de manera disociada los problemas de cada territorio ${ }^{48}$.

\footnotetext{
44 Sánchez, 1993.

45 IVDJ, E. 45, C. 59, doc. 402.

46 Billete de Felipe II (27 de febrero de I593), AGS, SSP, Milán, leg. I796, n. f.: «es fuerza que los tres estados de Italia se socorran unos a otros y que el Consejo y Junta del patrimonio se desvele en esto, con el cuidado y amor que yo fío de las personas que en la una y otra parte intervienen y que se me vaya consultando lo que pareciere».

47 Ver, a modo de ejemplo, las cuentas de I576: IVDJ, E. 45, C. 59, doc. 403.

${ }^{48}$ Ver las deliberaciones de la sesión de trabajo de la Junta del 18 de septiembre de I576: IVDJ, E. 45, C. 59,
} 
A pesar de las lagunas documentales en la producción de la Junta, todo invita a pensar que, acorde con las instrucciones, sus trabajos se movieron casi siempre en los dos campos determinados por el rey: uno lo constituían las soluciones propiamente financieras, con una atención especial al ámbito fiscal; la otra vertiente recayó en el fomento de una gestión más eficaz de los administradores de la monarquía, especialmente de los oficiales de justicia y de hacienda ${ }^{49}$.

\section{I. Numeración versus negociación (un caso napolitano)}

La revuelta de mayo de 1585 contra el Electo del pueblo Vicenzo Starace, en Nápoles, fue un detonante. Tres años escasos después de la visita general del reino llevada por Lope de Guzmán ${ }^{50}$, estallaba un motín que no hizo sino poner de manifiesto la corrupción de los oficiales y la mala gestión del virrey con la complicidad de las baronías locales. Tras la redada organizada por Madrid para castigar a los culpables que aún quedaban con vida, la situación se apaciguó. Pero en la corte, como resultado de esos acontecimientos, surgió la convicción de que la corona había de reforzar el control sobre los oficiales regios, especialmente los de justicia y de hacienda ${ }^{51}$. De ahí que, en 1590, Felipe II empezó a contemplar la posibilidad de recurrir a una «numeración $)^{52}$ del reino napolitano.

Por vía de la Junta de Patrimonio de Italia, el virrey recibió la orden de reunir a los regentes del Colateral, a los lugartenientes de la Sumaria y al procurador Fornaro para que determinasen la oportunidad o pertinencia de proceder a dicha numeración. La consulta, obviamente, había de ser secreta, pues los miembros de la Junta recordaban que: «[...] la hora que se entendiese que se trata de numeración los Pueblos esconderían y adulterarían los libros y catastros que tienen para sus colectas que es de donde se suele sacar la mayor prueba para la verificación de los fuegos $»^{53}$.

De esta primera etapa consultiva, resultó la absoluta necesidad de proceder al censo. Los hombres reunidos por el virrey abogaron de forma unánime a favor de esta solución, fundando su opinión en dos argumentos principales. El primero era que hacía más de treinta años que no se procedía a un recuento de los fuegos en Nápoles, y si no se hacía nada, en espacio de quince años «apenas

doc. 403.

49 Se entiende aquí el término «administrador» en el sentido de agentes más o menos autónomos, encargados del patrimonio y la justicia real, y no como la figura del burócrata de tipo weberiano, Descimon, Schaub y Vincent, 1997.

50 Peytavin, 2003.

${ }^{51}$ André, 2017.

52 numeración: procedimiento mediante el cual se procede al recuento de poblaciones, según el número de fuegos.

${ }^{53}$ AGS, SSP, Nápoles, leg. 6. 


\section{LA JUNTA DE PATRIMONIO DE ITALIA}

quedaría hombre que supiese dar razón dello porque todo sería confusión» ${ }^{54}$. La imprecisión de este argumento es sorprendente, pues en realidad la Corona no había procedido a una numeración en Nápoles desde 1547, es decir más de cuarenta años, y no treinta. Además, el argumento ocultaba el hecho de que en aquel año de 1547 el anuncio de la numeración bastó para provocar una revuelta ${ }^{55}$.

El segundo argumento era que el aumento del número de fuegos que se observaría con casi total certeza, no iba a ser homogéneo en todo el territorio. Esto significaba que la renuncia a la numeración y el dejar las cosas como estaban supondría reconocer, y así reforzar, el desequilibrado reparto del peso fiscal en el reino. Proceder a una numeración había de permitir restablecer la justicia $y$, por tanto, evitar descontentos populares.

En Madrid, el Consejo de Italia sostuvo la misma opinión, afirmando la urgencia de conocer con certeza con qué capacidad fiscal se podía contar en Nápoles. Podría sorprender un consenso tan amplio sobre una cuestión tan delicada, y más todavía cuando este consenso reunía actores locales y consejeros del rey en la corte. Sin embargo, no hay que dejarse engañar por esta aparente unanimidad. En realidad, las razones de defender la numeración eran muy diferentes en las dos penínsulas.

Para los consejeros en la corte era evidente que sin un control sistemático de las realidades locales era imposible gobernar territorios tan alejados de la cabeza de la monarquía. De hecho, la voluntad de reforzar el poder de los Consejos sobre las instituciones gubernamentales locales no era una especificidad de los asuntos italianos, sino una tendencia global que las grandes empresas de las Relaciones de Indias y de los pueblos de Castilla habían ido confirmando a lo largo de la década de los 70 del Quinientos. Además, conocer para mejor gobernar, conseguir informaciones para mejor adaptar los mecanismos de la decisión en la corte eran algunos de los fundamentos del recurso creciente a Juntas específicas $^{56}$. Sin embargo, en este caso, la numeración también había de servir de arma en el enfrentamiento entre las instituciones del gobierno sitas en la capital napolitana y las baronías del reino. Para los miembros de la Sumaria y del Colateral, la finalidad de la numeración no era sacar informaciones fidedignas sino hacerse con el control y la gestión de dichas informaciones para seguir controlando los mecanismos locales de la recaudación.

En opinión de los miembros de la Junta de Patrimonio esta solución era impensable. No convenía proceder a una numeración sino pactar con los poderes locales un aumento del número de fuegos. Recurriendo de esta manera a una

\footnotetext{
${ }^{54}$ AGS, SSP, Nápoles, leg. 6.

55 Pilati, 2015.

${ }^{56}$ André, 2019.
} 
práctica que venía de antiguo, los miembros de la Junta preconizaban negociar una cifra. Según ellos esta solución presentaba dos ventajas. En primer lugar, Madrid no parecería entrometerse en los asuntos del reino ni tratar de aumentar universalmente la presión fiscal. En otros términos, la negociación, en opinión de los miembros de la Junta, había de evitar el estallido de nuevos disturbios y garantizar la paz. En segundo lugar, y era lo más importante, las élites locales, viendo mantenida su autonomía y confirmada su autoridad en la gestión de la hacienda del reino, continuarían desempeñando su papel de correa de trasmisión de la política de la corona. Según los miembros de la Junta, la numeración no podía sino provocar descontentos, sin garantizar en absoluto que se fuera a averiguar verdad alguna en cuanto al número de habitantes del reino. Negociar el aumento de los fuegos era, por consiguiente, mucho menos conflictivo y no necesariamente menos lucrativo. Todo dependía de los resultados de la negociación.

Es interesante ver aquí como tanto los miembros del Consejo como los de la Junta blandieron la amenaza del motín para convencer al rey. Unos lo hacían arguyendo a favor de la justicia fiscal, mientras que los otros lo hacían, según un razonamiento opuesto, alegando que la numeración sería percibida como una injusticia. Los otros dos argumentos muestran en mi opinión el verdadero antagonismo entre la posición de cada colegio: mientras el Consejo de Italia consideraba a priori la necesidad de controlar lo local y pretendía extender su conocimiento, y por ende su dominio, a la totalidad del reino, la Junta de Patrimonio partía del principio de que los márgenes de acción dejados a los poderes locales constituían uno de los fundamentos del gobierno de Italia.

La decisión final fue ratificada unos meses más tarde por los miembros de la Junta personal de Felipe II que dieron la razón a los de la Junta de Patrimonio. Al margen de la consulta, el rey, agobiado por la tardanza, escribió:

No creo que es bien perderse en esto de la numeración más tiempo del que se ha perdido y para esto creo que sería bien escribir al virrey que, concertándose en que den tanto de renta como se entiende que se sacaría por la numeración, lo acete y se haga el concierto y que si no vinieren en ello se haga la numeración con la más orden y menos vejación que sea posible ${ }^{57}$.

La opinión de los miembros de la Junta de patrimonio subraya a mi juicio la oposición entre unos consejeros convencidos de la necesidad de reforzar el absolutismo madrileño (los del Consejo de Italia) y otros consejeros, más afines a soluciones pactadas y favorables a consensos negociados con los territorios. El conocimiento, la sabiduría y también, cabe decirlo, los propios intereses de los miembros italianos de la Junta asociados a la prudencia de su plantilla fija habían

57 IVDJ, E. 43, C. 55, doc. 347. 


\section{LA JUNTA DE PATRIMONIO DE ITALIA}

contribuido a elaborar una solución menos conflictiva, más consensual si se quiere, sin perder de vista los intereses de la corona.

\subsection{La farsa de las visitas de inspección (un ejemplo milanés)}

Tiene V. M. en Nápoles en la Sumaria de la puerta adentro donde se rige aquel tribunal más de quinientas personas en oficios diversos; ejercicios destos no son todos los que saben puntualmente el estado del patrimonio de aquel reino porque no conviene que todos lo sepan; pero de los principales ministros no hay ninguno que no lo entienda como el de su propia hacienda y desto se sigue grande utilidad porque cuando se trata de deliberar de hacer algún gasto o sobre hacer alguna provisión, acude uno con un camino y otro con otro y no depende la luz de las materias de uno solo [...] Pues si lo de Nápoles, que es un rincón, está desta manera, grande lástima es ver que la grandeza de lo de acá esté tan abreviada que se pueda decir que no hay a quién pedir razón de ninguna cosa fuera de uno con ser en número los ministros muchos ${ }^{58}$.

Estas observaciones del viejo y experto licenciado Francisco de Ávalos, eran, ya para el año 1576, poco novedosas. Su memorial, al igual que otros muchos, llamaba la atención del rey sobre el excesivo número de malos consejeros en los reinos y en la corte $y$, asimismo, sobre el escaso número de aquellos que servían con eficacia los intereses de la Corona. Sin embargo, el discurso desarrollado por Ávalos también llegaba a la conclusión de que, de un número amplio de ministros competentes y oficiales expertos en asuntos hacendísticos, dependía la «luz de las materias», es decir: este cuerdo consejo, capaz de sacar la decisión real de las tinieblas en la que tendía a sumarlo una diversidad abrumadora de territorios que redundaba en una cantidad inabarcable de instituciones locales.

Sin duda alguna, esta observación era compartida por muchos consejeros en la corte $y$, entre ellos, los miembros de la Junta de Patrimonio de Italia en la que, recordémoslo, Ávalos participaba. Pero en 1576 estos últimos fueron más allá de la simple observación, y trataron de establecer responsabilidades y, obviamente, de ofrecer al monarca soluciones adaptadas a los contextos italianos. Para ellos, la causa principal del mal endémico apuntado por Ávalos había de encontrarse en la ineficacia de las visitas de inspección. Esta argumentación tampoco era nueva. Pero, en general, las críticas formuladas en contra de los procedimientos de control - visitas y juicios de residencia principalmente- conducían casi siempre a una misma conclusión: o bien los jueces visitadores eran incapaces, o bien eran corruptos ${ }^{59}$. Sobre esta cuestión, no obstante, la Junta de Patrimonio de Italia ofrece perspectivas más complejas.

58 IVDJ, E. 24, C. 37, doc. I 13. Memorial de Francisco de Ávalos dirigido al rey, 4 de noviembre de 1576.

${ }^{59}$ Rivero Rodríguez, 1998a. 
Baltasar de Molina, miembro de la Junta, antiguo Gran Canciller de Milán y revisor de cuentas del ducado durante la visita general de los años 1560, había redactado un memorial que fue examinado por la Junta y sometido al soberano el 24 de noviembre, unas semanas después de su creación. En ese memorial, Molina explicaba de forma pormenorizada que la poca utilidad de las visitas y la tardanza de los procedimientos se debían ante todo al hecho de que:

[...] primero que entienden la tierra y conoscen las gentes caen [los jueces visitadores] en los caminos de las malas negotiationes, los han subplantado y hecho entender que sea lo blanco negro y al contrario, $y$ les han subornado sus criados y oficiales y no sirven como digo de castigo, sino de dar ánimo viendo que nada sale a luz ni se averigua ${ }^{60}$.

Cuando finalmente los jueces visitadores «abren los ojos», concluía Molina, siempre es demasiado tarde. Se les ordena entonces acabar su comisión, y vuelven a Madrid con las manos vacías, dejando los reinos visitados en peor estado que antes de la visita.

Sin embargo, según los miembros de la Junta de Patrimonio, el problema no radicaba en la corrupción o incapacidad de los jueces sino en el método general de las visitas. Este método, aducían los hombres de la Junta, siempre había consistido en colectar testimonios para utilizarlos en contra de los propios oficiales sospechosos. De esta forma, afirmaban, no había manera de sacar nada en claro:

La manera con que se visita agora es tomando testigos de los subornos y de las malas administraciones, de los malos contratos y cosas de los oficiales; $y$ por esta vía no es posible saber nada, porque el que soborna o presenta no lo dirá y el que tuvo el contrato y fue a la parte con el oficial, menos; y mayormente en Italia o parte dependiente della porque la manera general de negociar allí todos es esta y a esta causa el que lo dijese ultra de ser tenido por infame entre ellos se privaría de la negociación ${ }^{61}$.

En realidad, el problema no tenía que ver con la suficiencia o la integridad de los jueces sino con su profundo desconocimiento de las costumbres locales y con el tener que enfrentarse con solidaridades poderosas. En opinión de Molina y de los hombres de la Junta, en estas condiciones, tanto valía confiarle la visita directamente a un ladrón ${ }^{62}$. Pero lo interesante del caso no era tanto que este

\footnotetext{
60 Memorial de Baltasar de Molina al rey (24 de noviembre de I576), IVDJ, E. 24, C. 37, doc. I20. Esas mismas ideas se hallaban resumidas en la fórmula: «en cada nueva visita se toma un hombre nuevo que ni conoce ni sabe la tierra ni la gente».

61 IVDJ, E. 24, C. 37, doc. 120

62 IVDJ, E. 24, C. 37 , doc. 120.
} 


\section{LA JUNTA DE PATRIMONIO DE ITALIA}

razonamiento daba por inútiles los procedimientos de control de los oficiales regios, como que las soluciones propuestas por los miembros de la Junta de $\mathrm{Pa}$ trimonio suponían un cambio metodológico profundo.

Primero, proponían dejar de castigar con simples multas a los oficiales locales que se sospechaba cometían prácticas delictivas. En cierta manera, había que imponerles el peor castigo que podían temer: trasladarlos en el momento mismo en el que, en Madrid, los consejeros se enteraban de que no hacían su trabajo como era debido, y darles un nuevo destino. Ciertamente, esta solución era susceptible de remitir a otros lugares los mismos problemas; pero, a lo mejor, viéndose desterrados y apartados de sus negocios, los oficiales escarmentarían. Además, esta estrategia permitiría neutralizar determinadas prácticas corruptivas sin tener que recurrir a una onerosa visita.

Lo segundo que proponían los miembros de la Junta concernía la forma de llevar a cabo la visita. Siguiendo un ejemplo sacado de la experiencia de Molina en Milán, insistían en la necesidad de que los jueces visitadores realizasen parte de sus pesquisas cerca de los artesanos y oficiales mecánicos. Para demostrarlo sacaban a colación el ejemplo de ciertos «polleroles» (sic) de los senadores milaneses, que revendían las aves no consumidas sin pagar ningún derecho, añadiendo que lo mismo pasaba con cereros, especieros y otros. Había aquí, según Molina, un tráfico lucrativo del que, de investigarse, «se sacarían mil cosas que ofenderán las reales orejas de S. M. ${ }^{163}$. En otros términos, se trataba de sustituir la denuncia por una investigación sobre trapicheos comunes y corrientes vinculados al consumo.

En cuanto a los oficiales reales, cabía cambiar radicalmente la tipología de los cuestionarios a los que había que someterlos. En lugar de preguntarles, como era costumbre, si sabían si tal o cual oficial había cometido tal o cual agravio, se trataba de interrogarles

[...] sobre qué hacienda se metió en servicio de V. M. y de dónde y cómo le vino; la otra qué salario o entretenimiento ha tenido y qué ha gastado al año; $y$ dado y después de dónde ha habido las posesiones que valen a treinta y a cuarenta mil ducados; de dónde han habido las rentas de dos y tres y cuatro mil ducados de renta; $y$ de qué han casado sus hijos y hijas y les han dado dote y rentas; $y$ de qué tienen plata que vale de cuatro y cinco mil ducados y muebles de más de seis mil $y$ aun de ocho ${ }^{64}$.

La primera pregunta se refería al hecho de que para comprar oficios muchos se endeudaban. Era algo común, pero iba creciendo la conciencia en Madrid

${ }^{63}$ IVDJ, E. 24, C. 37, doc. 120.

${ }^{64}$ IVDJ, E. 24, C. 37, doc. 120. 
de que el problema de la venalidad de los oficios no era tanto una cuestión de ética relacionada al cumplimiento del oficio como un problema de clientelismo y de deudas personales. Así lo formulaba unos años más tarde el regente Moles, encargado de examinar las candidaturas al puesto de secretario del Consejo Colateral en Nápoles, en I589: a los que no tienen dinero suficiente para comprar el oficio, explicaba, se lo prestan «personas que querrán ser participantes en el oficio y en los fructos dél [...] y en esto sería muy perniciosa cosa, como se deja entender, habiendo de tener un secretario dentro del Consejo y muchos fuera» ${ }^{65}$.

Las otras preguntas propuestas por la Junta tendían a determinar las ganancias y gastos de los oficiales para luego poder evaluar sus capacidades adquisitivas. «Posesiones» y «rentas» constituían el núcleo del interrogatorio remontando así la pista de la fuente de los ingresos y de la fortuna de los oficiales. Finalmente, las dotes y contratos de casamiento, quizá también los mayorazgos fundados, habían de ser indicadores de las cantidades manejadas por dichos oficiales.

Según la Junta de Patrimonio, esta simple serie de preguntas habría de ser suficiente como para derrotar toda estrategia de ocultación de dinero y para desentrañar todo tipo de corrupción. En suma, para ellos, era inútil tratar de engañar con testimonios y denuncias a oficiales que tenían mucho más que perder hablando que callándose. La única manera de sacar en claro las prácticas corruptivas del reino consistía en seguir la pista del dinero.

Estos casos, escogidos entre los escasos expedientes que nos han llegado de la Junta, son reveladores de mecanismos específicos de concertación en la corte. No creo que se tratara de cortocircuitar al Consejo de Italia ni de promover a actores que o bien se encontraban ya en la cúspide del poder, o bien no habrían de quedarse mucho tiempo en Madrid. Más bien se trataba aquí de delegar, en cierto modo, parcelas de deliberaciones a expertos cuya experiencia del terreno permitía emitir opiniones más acordes con las circunstancias. A visiones a veces un tanto desconectadas de las coyunturas y de las que podían resultar decisiones inadaptadas, la Junta oponía lecturas más amplias de lo que podía o no estar en juego en tal o cual momento. Esto se hace evidente en el caso de la numeración. Pero también lo es en el caso de las visitas que tendieron a ser cada vez más frecuentes en el transcurso de los años 1570-1580 y que necesitaban ser discretamente reformadas.

${ }^{65}$ Capítulo de carta del regente Moles a Zayas (17 de febrero de I589), AGS, SSP, Nápoles, leg. 6. 


\section{LA JUNTA DE PATRIMONIO DE ITALIA}

De estas deliberaciones de la Junta emerge también la voluntad por parte del soberano y de sus consejeros de multiplicar y diversificar las vías de acción de Madrid en sus diferentes territorios. Esto no significaba reafirmar de forma autoritaria el poder de la corte sobre las posesiones de la monarquía, sino potenciar la capacidad negociadora del gobierno. Si es cierto que el rey necesitaba oficiales obedientes y fieles consejeros, también le hacía falta valerse de agentes capaces de elaborar compromisos, de matizar las informaciones y también capaces de considerar la acción política como un conjunto de herramientas interconectadas y complejas, lo que, a todas luces, habían de cumplir los miembros itinerantes de la Junta. De este arte de la negociación «erigida en principio de acción», para retomar la fórmula de Anne Dubet ${ }^{66}$, había de resultar una mayor resiliencia, una suerte de cohesión mediante el consenso político, la autonomía financiera y un control razonable de los oficiales reales locales.

\section{CONCLUSIONES}

Este ejemplo de funcionalidad de Junta no es fácil de encasillar en una tipología precisa. Ciertamente, la Junta tenía que asesorar al rey y dirimir, puntualmente - pues no todos los asuntos italianos eran sometidos al examen de la Junta-, casos específicos. Pero es que, además, constituía, también a nivel de la corte, una plataforma nueva de información a caballo entre la Tesorería general de la Corona de Aragón, el Consejo de Italia y en algunos casos las Contadurías y el Consejo de Hacienda. La Junta de Patrimonio de Italia formaba parte de aquellas Juntas que, como la Junta Grande de 159/67 o la Junta para la Armada del Mar Océano de $1594^{68}$, permitían liberar la consulta de una aproximación estrictamente jurisdiccional para insertarla en estrategias gubernativas más amplias.

Pero la finalidad más interesante de esta Junta quizá haya de buscarse, precisamente, en el vínculo nuevo que establecía entre la corte y los reinos. Haciendo eco al artículo pionero de Guido D'Agostino, publicado en 1993, titulado: «La formación del Estado moderno en los territorios italianos bajo la dominación española: Nápoles, Sicilia y Cerdeña en los siglos XV-XVIII ${ }^{69}$, Ana Minguito Palomares, en su obra sobre el virrey Oñate escribió lo siguiente:

[...] España conseguirá en el mediodía italiano y mediterráneo un delicado equilibrio entre el dominio y el consentimiento, gracias a cuatro compromisos que han

\footnotetext{
${ }^{66}$ Dubet, 1999.

${ }^{67}$ André, 2018b.

${ }^{68}$ André, 2015.

${ }^{69}$ D'Agostino, 1993-1994.
} 
caracterizado su práctica de gobierno en el reino de Nápoles: entre la monarquía y la aristocracia feudal; entre la monarquía y la capital; entre el sistema fiscal y los operadores económicos privados; entre el fisco y el Estado... ${ }^{70}$

Esta relación entre autoridad y consentimiento ${ }^{71}$ se fundamentaba en compromisos acordados en distintos niveles entre la corona y las élites locales napolitanas, sicilianas y milanesas, las cuales aceptaban defender la paz social a cambio de autonomía y de poderes financieros. Sin embargo, a este equilibrio entre autoridad y consentimiento se le ha dado un aire de esencialidad, cuando conviene más bien subrayar su fragilidad y las constantes renegociaciones que implicaba. Obviamente, siempre es en los meses que siguen a las revueltas populares cuando saltan a la vista los procesos de renegociación del pacto entre la Corona y su territorio ${ }^{72}$. Pero fuera de estos procesos extraordinarios, el compromiso entre Madrid y sus posesiones se iba construyendo de forma menos visible en la gestión cotidiana de los asuntos.

Es en esta perspectiva en la que cabe analizar la Junta de Patrimonio de Italia: como un mecanismo de elaboración de compromisos y mantenimiento ordinario del pacto político que unía la Corona con sus territorios de la península itálica.

\section{BIBLIOGRAFÍA}

Álvarez-Ossorio, Antonio, Milán y el legado de Felipe II. Gobernadores y corte provincial en la Lombardía de los Austrias, Madrid, Sociedad Estatal para la Conmemoración de los Centenarios de Felipe II y Carlos V, 2001.

André, Sylvain, «Les Juntes de Philippe II: expertise, bureaucratie, gouvernement», Cahiers d'études romanes, 30, 20I5, pp. 327-35I.

André, Sylvain, «Le peuple contre Sancho Bastida de Muñatones. Noblesse et officiers royaux dans la révolte napolitaine de 1585», Cahiers d'études romanes, 35, 2, 2017, pp. 245-266.

André, Sylvain, «Gouverner par juntas. Révision historiographique d'une méthode gouvernementale (Monarchie hispanique, seconde moitié du XVle siècle)», Revue d'histoire moderne et contemporaine, 65, 3, 2018a, pp. 7-32.

André, Sylvain, «Prêts volontaires, emprunts forcés et impôt universel. La Junta grande et les aléas de la négociation au lendemain de la signature du premier servicio de los ocho Millones», e-Spania, 30, $2018 \mathrm{~b}$.

André, Sylvain, «El momento ovandino. De la empresa de saber a la fábrica de la acción», e-Spania, 34, 2019.

André, Sylvain, Le Minotaure en son labyrinthe. La Junta de Philippe II et le gouvernement de la Monarchie hispanique (I586- /602), Paris, Éditions hispaniques, 2020.

D’Agostino, Guido, «La formación del Estado moderno en los territorios italianos bajo la dominación española: Nápoles, Sicilia y Cerdeña en los siglos XV-XVII», Chronica Nova, 21 , 1993-1994, pp. I43-I59.

Descimon, Robert, Jean-Frédéric Schaub, y Bernard Vincent (dirs.), Les figures de l'administrateur. Institutions, réseaux, pouvoirs en Espagne, en France et au Portugal. XVIe-XIXe siècle, Paris, EHESS, 1997.

70 Minguito Palomares, 2011, p. 162-164.

7I Zúñiga, 2013.

72 Hugon y Merle, 2016. 


\section{LA JUNTA DE PATRIMONIO DE ITALIA}

Dubet, Anne, «Le servicio de los 8 millones (1588-1590) ou la négociation érigée en principe d'action», Ibérica, II, 1999, pp. 45-65.

Escudero, José Antonio, Felipe II. El rey en el despacho, Madrid, Universidad Complutense, 2002.

Fernández Conti, Santiago, «La nobleza cortesana: don Diego de Cabrera y Bobadilla, tercer conde de Chinchón», en La corte de Felipe II, ed. José Martínez Millán, Madrid, Alianza editorial, 1994, pp. 229-270.

Gaudin, Guillaume, Penser et gouverner le Nouveau Monde. L'empire de papier de Díez de la Calle, commis du Conseil des Indes, Paris, L'Harmattan, 2012.

Hugon, Alain y Alexandra Merle (dirs.), Soulèvements, révoltes, révolutions dans l'empire des Habsbourg d'Espagne, XVle-XVIle siècle, Madrid, Casa de Velázquez, 2016

Martínez Millán, José y Carlos José de Carlos Morales (dirs.), Felipe II (I527-1598). La configuración de la Monarquía Hispana, Salamanca, Junta de Castilla y León, Consejería de Educación y Cultura, 1998.

Minguito Palomares, Ana, Nápoles y el virrey conde de Oñate. La estrategia del poder y el resurgir del reino (I6481653), Madrid, Sílex, 20II.

Musi, Aurelio, «El reino de Nápoles y el sistema imperial español», en Felipe II (I527-/598) Europa y la Monarquía católica, ed. José Martínez Millán, Madrid, Ediciones Parteluz, 1998, I, 2, pp. 555-565.

Muto, Giovanni, «Le conseil collatéral du royaume de Naples», en Conseils et conseillers dans l'Europe de la Renaissance (ca. 1450-ca. I550), ed. Cédric Michon, Rennes, Presses universitaires François-Rabelais de Tours-Presses universitaires de Rennes, 2012, pp. 21।-24I.

Peytavin, Mireille, «Españoles e italianos en Sicilia, Nápoles y Milán durante los siglos XVI y XVII: sobre la oportunidad de ser "nacional” 。 "natural”», Relaciones, 73, I998, vol. XIX, Pp. 86-II4.

Peytavin, Mireille, Visite et gouvernement dans le royaume de Naples (XVI-XVII siècles), Madrid, Casa de Velázquez, 2003.

Pilati, Renata, Arcana seditionis: violenze politiche e ragioni civili, Napoli I547-I557, Napoli, Instituto Italiano per gli Studi filosofici, 2015.

Riba García, Carlos, Correspondencia privada de Felipe II con su secretario Mateo Vázquez (I567-/59I), Madrid, CSIC, 1959.

Rivero Rodríguez, Manuel, «Buen gobierno y ejemplaridad. La visita del Consejo de Italia», en Felipe II (I5271598) Europa y la Monarquía católica, ed. José Martínez Millán, Madrid, Ediciones Parteluz, I998a, I, 2 Pp. 705-730.

Rivero Rodríguez, Manuel, Felipe Il y el gobierno de Italia, Madrid, Sociedad Estatal para la Conmemoración de los Centenarios de Felipe II y Carlos V, 1998b.

Rivero Rodríguez, Manuel, «El dilema de los letrados, servir al rey y a la fe: Francisco Hernández de Liébana», Libros de la corte, Monográfico I, año 6, 2014, pp. 277-292.

Sánchez, Dolores María, El deber de consejo en el estado moderno: las Juntas «ad hoc» en España (I474-I665) Madrid, Polifemo, 1993.

Zúñiga, Jean-Paul, Négocier l'obéissance/Negociar la obediencia. Autoridad y consentimiento en el mundo ibérico en la época moderna, Granada, Editorial Comares, 2013. 